\title{
A casa como espaço de leitura e as maneiras de ler: desvelando as preferências de universitários de Letras e de Pedagogia
}

\section{The house as a reading space and the ways of reading: knowing the preferences of university students of Letters and Pedagogy}

Deisi Luzia Zanatta ${ }^{1}$ https://orcid.org/0000-0001-7356-1499

RESUMO: Este artigo visa a descrever e analisar os espaços e maneiras de ler, especialmente, os que se referem ao ato de ler no espaço da casa e as disposições físicas de leitura em ambientes privados dos estudantes ingressantes nas licenciaturas de Letras e de Pedagogia de três universidades brasileiras. Trata-se de um estudo qualitativo e quantitativo, resultado final de uma pesquisa desenvolvida na Universidade de Passo Fundo, de 2015 a 2019, que, por sua vez, foi um desdobramento de um Procad - Projeto de Cooperação Acadêmica Interinstitucional cujas universidades integrantes foram: Universidade Estadual Paulista "Júlio de Mesquita Filho" (UNESP), campus de Assis, de Marília e de Presidente Prudente, Universidade Federal do Espírito Santo (UFES) e Universidade de Passo Fundo (UPF). Os dados obtidos mostraram que a leitura, quando realizada no interior da casa, permite ao leitor tomar determinadas liberdades com os textos no que se refere às disposições físicas, mas também evidenciaram que algumas maneiras de ler oriundas do Antigo Regime ainda são praticadas pelos respondentes da pesquisa.

\footnotetext{
${ }^{1}$ Doutora em Letras pela Universidade de Passo Fundo (UPF). Professora Tutora On-line da Católica de Santa Catarina - Centro Universitário Católico, de Jaraguá do Sul. E-mail: deisil.zanatta@gmail.com
} 
Palavras-chave: Leitura em licenciatura de Letras e de Pedagogia; casa como espaço de leitura; maneiras de ler.

ABSTRACT: This article aims to describe and analyze the spaces and ways of reading, especially those referring to the act of reading in the home space and the physical dispositions of reading in private environments of the students beginning in the undergraduate degrees of Letters and Pedagogy of three Brazilian universities. This is a qualitative and quantitative study, the end result of research developed at University of Passo Fundo (UPF), from 2015 to 2019, which, in turn, was a development of a Procad - Interinstitutional Academic Cooperation Project whose member universities were: Paulista State University "Júlio de Mesquita Filho" (UNESP), Assis, Marília and Presidente Prudente campus, Federal University of Espírito Santo (UFES) and University of Passo Fundo (UPF). The data obtained showed that reading when done inside the house allows the reader to take certain liberties with the texts regarding the physical dispositions but also showed that the some ways of reading from the Old Regime still practiced by the research respondents.

Keywords: Reading in literature and Pedagogy; the house as a reading space; ways to read.

\section{Introdução}

Nosso objetivo, neste estudo, visa a descrever os espaços e modos de ler, especialmente os que se referem ao ato de ler no espaço da casa e as disposições físicas de leitura em ambientes privados dos estudantes ingressantes nas licenciaturas de Letras e de Pedagogia. Vale enfatizar que o presente artigo é o resultado final de uma pesquisa desenvolvida na Universidade de Passo Fundo (UPF), de 2015 a 2019, estudo esse que, por sua vez, se originou de um desdobramento da pesquisa Leitura nas licenciaturas: espaços, materialidades e contextos na formação docente, resultado de um Projeto de Cooperação Acadêmica Interinstitucional - Procad do qual foram integrantes as seguintes instituições de ensino superior: Universidade Estadual "Júlio de Mesquita Filho" (UNESP), de Assis, de Marília e de Presidente Prudente, Universidade Federal do Espírito Santo (UFES) e Universidade de Passo Fundo (UPF).

O instrumento de pesquisa que originou este estudo se deu através do resultado de um questionário impresso aplicado aos acadêmicos ingressantes, maiores de 18 anos, totalizando 455 sujeitos, em cursos presenciais de Letras e de Pedagogia das universidades participantes do Procad na primeira semana de março de 2014.

Optamos pela análise e descrição da casa como espaço de leitura e as maneiras de ler 
em ambientes privados, a fim de conhecer a representatividade de tal espaço no que se refere à leitura e se as posições escolhidas para essa prática em lugares particulares são mais libertas ou tradicionais. Também, devido à extensão da pesquisa desenvolvida, não foi possível abarcar aqui todos os dados analisados.

No nosso entendimento, a leitura é primordial para a formação do pensamento crítico dos sujeitos. Logo, os professores de Letras e de Pedagogia atuarão diretamente com essa questão, pois a área do conhecimento que compreende a formação durante suas trajetórias nesses cursos superiores envolvem o estudo e interpretação de texto e, a partir disso, uma possível relação do escrito com o mundo.

Para tal, nos auxiliaram como base norteadora, no cotejo com a análise e descrição dos resultados obtidos, os pressupostos teóricos de Gaston Bachelard (1993), Roger Chartier (1991, 1998, 1999), Vincent Jouve (2002), Michèle Petit (2009, 2013) e Márcia Abreu (2001).

Para desenvolvermos a discussão aqui proposta, organizamos o presente trabalho da seguinte forma: a metodologia; as considerações teóricas e a descrição e análise dos dados obtidos no que se refere à casa como espaço de leitura; na sequência, apresentação e análise dos resultados sobre as maneiras de ler em espaços privados e, por fim, as considerações finais.

\section{Metodologia}

A área do conhecimento que compreende as Ciências Humanas se apoia, na maioria dos casos, em pesquisas qualitativas e, também, muitas vezes, quantitativas, que se preocupam em estudar a particularidade de um determinado acontecimento, com o objetivo de analisá-lo profundamente.

Diante dessas considerações, a técnica utilizada para a coleta dos dados, direcionada aos 455 sujeitos ingressantes em cursos presenciais de Letras e de Pedagogia das três instituições de ensino superior integrantes do Procad se deu através de um questionário impresso aplicado no mês de março no início do semestre letivo de 2014. Reunindo perguntas fechadas e abertas, respeitando o anonimato dos respondentes, o principal objetivo do questionário foi analisar o perfil leitor de universitários ingressantes nas licenciaturas de Letras e Pedagogia, de quatro universidades brasileiras, apontando princípios, conhecimentos e ações pedagógicas para a formação de leitores na universidade como espaço privilegiado de mediação da leitura e de circulação de práticas de leitura. 
No total, o questionário contou com 85 questões, estruturado em duas partes "Perfil dos sujeitos" e "Perfil leitor" e contemplou questões objetivas e discursivas que acolheram os seguintes itens: dados pessoais, tipos de textos lidos habitualmente, o que procura ler e por que motivo, suportes de leitura, espaços de leitura, tempos de leitura, dimensões valorizadas na leitura e indicação de uma preferência específica, que hábitos possui antes, durante e depois da leitura.

O resultado obtido foi separado nos seguintes blocos temáticos: "Espaços e modos de ler", "Gêneros textuais", "Estratégias de leitura", "Materialidade", "O papel das instituições e dos mediadores" e "Suportes de textos" e, posteriormente em uma reunião, as coordenadoras das equipes envolvidas dividiram o conteúdo conforme afinidades com os temas e linhas de pesquisa em que atuavam em suas respectivas universidades. $O$ trabalho que aqui apresentamos se enquadrou na seção "Espaços e modos de ler".

Vale enfatizar que tal trabalho englobou três instituições distintas e alicerçadas em contextos diferentes. Contudo, tivemos acesso à soma dos dados de todas as universidades integrantes do Procad, o que nos permitiu ter uma visão geral dos resultados do questionário aplicado aos ingressantes de Letras e de Pedagogia. Como não obtivemos as informações nas quais constavam os resultados separados por instituição, não foi possível analisarmos os diferentes contextos e compararmos os produtos. Ressaltamos que tal estudo diz respeito somente aos ingressantes da graduação desses cursos, porque o questionário não foi aplicado aos estudantes concluintes das instituições de ensino superior do Procad.

No intuito de interpretarmos os resultados obtidos a partir do questionário aplicado aos ingressantes de Letras e de Pedagogia das universidades integrantes do Procad, buscamos na teoria proposta por Carlo Ginzburg (1989), a respeito do paradigma indiciário, maneiras para compreender como algumas pistas que nos são dadas podem ser configuradas em um texto. De acordo com o historiador italiano, por volta do final do século XIX, surgiu silenciosamente na área das ciências humanas um modelo epistemológico ou paradigmático, sobre os quais, até o presente momento, não foi dada uma atenção merecida. A análise desse paradigma tende a contribuir "a sair dos incômodos da contraposição entre "racionalismo" e "irracionalismo" (GINZBURG, 1989, p. 143).

Ginzburg (1989) enfatiza que as raízes do paradigma indiciário remontam às origens da humanidade quando, por motivos de sobrevivência, o homem desenvolveu algumas habilidades baseadas em pistas. A transmissão do conhecimento acontece porque o homem possui a capacidade de criar e interpretar formas de linguagem. Essa linguagem pode ser falada, escrita ou através de gestos, expressões artísticas, pistas ou indícios deixados no caminho. Em 
sua trajetória ao longo do tempo, o homem, por muitos anos, foi caçador e, para obter êxito em sua caçada, precisava identificar as formas e movimentos das presas invisíveis pelas marcas/pistas que essas deixavam, como pegadas na lama, tufos de pelos, ramos quebrados, plumas emaranhadas, odores estagnados, etc.

Logo, para realizarmos a análise aqui proposta, nos baseamos nos pressupostos de Carlo Ginzburg (1989) sobre o paradigma indiciário, isto é, a partir das pistas, indícios dos resultados obtidos através do questionário aplicado aos ingressantes de Letras e de Pedagogia realizamos nossas interpretações sobre os ambientes e modos de ler mencionados por esses sujeitos bem como alinhavamos nossas inferências com a Teoria da História Cultural e dos Espaços e maneiras de leitura.

\section{A casa como espaço de leitura}

Conforme o dicionário Houaiss (2004, p. 140), casa designa construção destinada a habitação; morada de uma família; lar; o conjunto dos membros de uma família. Logo, a casa desde muito cedo exerce fundamental importância na vida das pessoas. Após nosso nascimento é para ela que nos direcionamos. Nesse ambiente, crescemos e vamos construindo a nossa intimidade e, consequentemente, a nossa identidade. É a casa que nos abriga e protege das adversidades que acontecem no espaço exterior.

De acordo com Gaston Bachelard (1993), a casa é o nosso canto no mundo, o nosso primeiro universo. Em suma, um verdadeiro cosmos no qual se integram os pensamentos dos seres humanos, bem como tudo o que o homem lembra e sonha. A casa, na vida do homem, afasta contingências, multiplica seus conselhos de continuidade e também, mantém o homem através das tempestades do céu e da vida. Sem ela, enfatiza o estudioso, o homem seria um ser disperso. Assim, conforme Bachelard parece que a imagem da casa se transforma na topografia de nosso ser íntimo, ao mesmo tempo, que é imaginada como um ser concentrado, que nos convida a uma consciência de centralidade.

De acordo com Jean Goulemot (1991), a casa se opõe à organização do espaço urbano, praças, cafés, restaurantes, enfim, logradouros públicos, que coloca sob o olhar de autoridade e da comunidade parte das atividades das pessoas. A representatividade desse espaço, então, vai muito além da proteção. Ela representa liberdade, lugar onde as pessoas podem, de certa maneira, se expressar livremente, onde nos exilamos dos desgastes físicos e psicológicos das 
pressões diárias, seja da escola, da universidade ou do trabalho.

A casa, em suma, representa o local no qual depositamos todas as nossas experiências sejam elas físicas, emocionais ou intelectuais, benéficas ou maléficas. Deste modo, as recordações do passado, na maioria das vezes, se relacionam com a casa, pois esta é um espaço de reflexão das ações que praticamos dentro e fora dela. A casa, assim, é nossa memória, consciente e inconsciente e como a mente, organiza cognitiva e emocionalmente toda a continência que nos forma como sujeitos capazes de compreender a nós mesmos e atuar na sociedade em que vivemos.

Roger Chartier (1998), por sua vez, é enfático ao postular que com as modificações que ocorreram nas sociedades durante o curso da história, os espaços de leitura foram os mais diversos possíveis, ocasionando aos indivíduos, muitas vezes, a "controlar suas condutas, a censurar seus movimentos espontâneos e a reprimir seus afetos" (CHARTIER, 1998, p. 78). Contudo, a partir do século XVIII, o leitor pôde experimentar práticas mais livres em relação à leitura, porque esta, pouco a pouco, foi se expandindo e ganhando novos espaços.

Devido à sua relevância e representação, a casa como ambiente de leitura exerceu forte influência sobre os acadêmicos que responderam aos questionamentos da pesquisa. Com isso, apresentamos, a seguir, as questões que dizem respeito às práticas de leitura dos ingressantes de Letras e de Pedagogia das instituições integrantes do Projeto de Cooperação Acadêmica Interinstitucional.

A questão $51^{2}$ apresentou o seguinte:

\footnotetext{
${ }^{2}$ Os licenciandos participantes da pesquisa tinham a opção de assinalar mais de uma resposta, por isso o número dessas pode se apresentar superior ao total de sujeitos respondentes. Tal questão se insere nos seguintes blocos temáticos: Perfil leitor, Espaços e modos de ler e O papel das instituições e dos mediadores.
} 


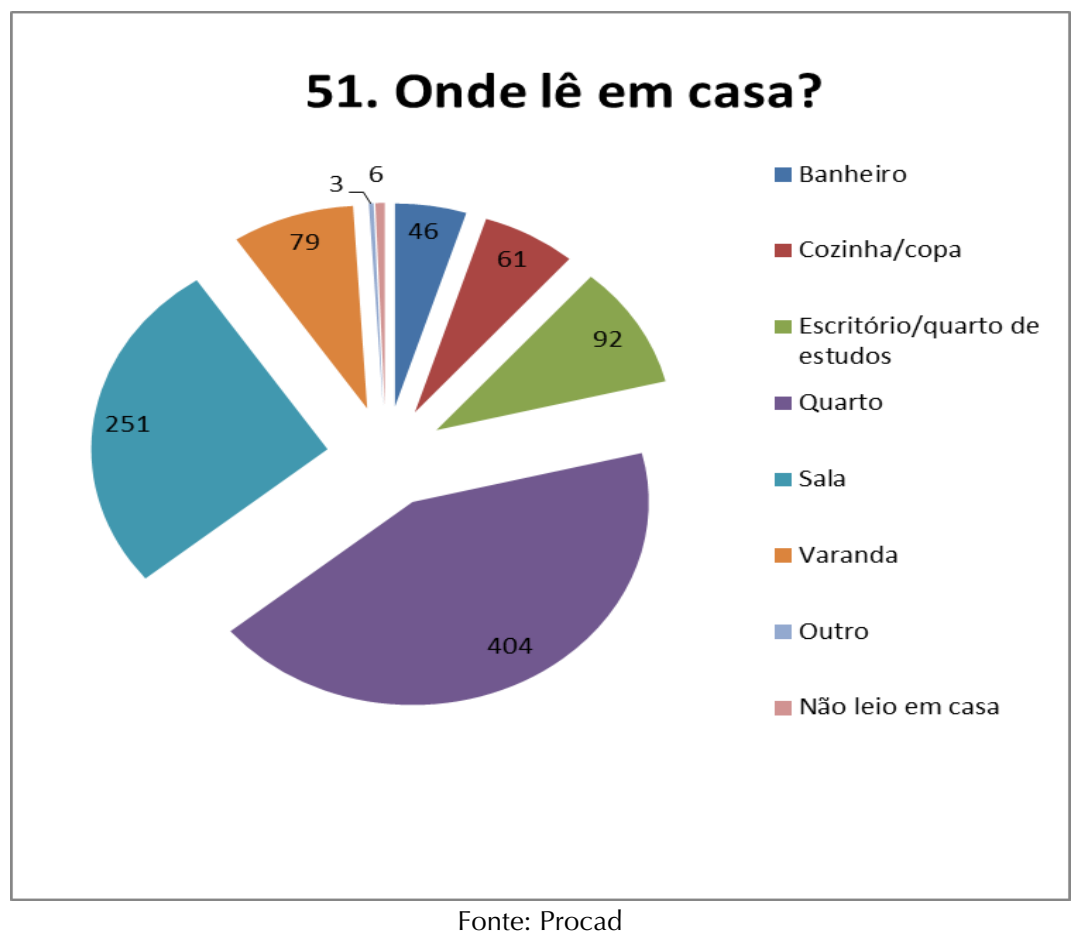

Dentre os acadêmicos que responderam ao questionário, 404 alegaram que quando praticam a leitura em casa, o quarto se configura como espaço preferido, enquanto que 92 alunos mencionaram ler no escritório ou quarto de estudos, 61 respondentes na cozinha. Já 48 estudantes afirmaram ler no banheiro, 79 sujeitos responderam que optam por ler na varanda, 251 alegaram que o lugar preferido é a sala e 6 afirmaram não praticar a leitura em casa.

Percebemos que o lugar mais frequentado para a prática leitora é o quarto. Podemos entender que os que a realizam nesse espaço, certamente, optam por uma leitura mais complexa, teórica como também de foro íntimo, um tipo de leitura voltado para a expressão dos sentimentos, para um diálogo consigo mesmo. Diante disso, "ler é portanto a oportunidade de encontrar um tempo para si mesmo, de forma clandestina ou discreta, tempo de imaginar outras possibilidades e reforçar o espírito crítico" (PETIT, 2008, p. 56).

De acordo com Vincent Jouve (2013), toda leitura tem uma parte constitutiva de 
subjetividade e, a partir disso, postula duas dimensões subjetivas do ato de ler. A primeira é a subjetividade necessária, aquela em que a implicação do leitor é necessária quando estruturalmente exigida pelo texto. Isto é, as operações de leitura requerem o investimento pessoal do leitor, como é o caso do processo de representação em que as imagens mentais elaboradas pelo receptor a partir do texto se dão pela incompletude estrutural da obra, necessariamente subjetivas. Como complemento a isso, o modo pelo qual o leitor imagina o cenário e as personagens da obra remetem às situações vivenciadas por ele cujas lembranças surgem espontaneamente durante a leitura.

Já a subjetividade acidental ocorre quando em determinados momentos do ato de ler, o leitor é conduzido pelo texto a se envolver pessoalmente na ficção inserindo a subjetividade num espaço onde ela não estava prevista pelo texto. Assim, às ordenações acidentalmente subjetivas se somam as composições acidentalmente subjetivas. Daí, deduzimos que "a confrontação do leitor consigo mesmo é, portanto, uma das dimensões maiores da leitura" (JOUVE, 2013, p. 61) e, com isso, o quarto permite a individualização da leitura, porque possibilita ao leitor viver, experienciar o texto. As emoções emergidas da leitura fazem com que o leitor possa se identificar com as situações do texto, ocasionando, então, as ilusões referenciais ${ }^{3}$.

No quarto, espaço íntimo, o leitor se permite a uma relação mais envolvente e livre com o livro, onde não precisa reprimir a sua emoção e subjetividade, o que significa que "essa leitura é uma atividade íntima e sossegada, no mais das vezes solitária, que mais leva à meditação do que à mudança ou à ação" (POULAIN, 1989, p. 78). Também, tal ambiente também pode abrigar objetos de preferência do sujeito tais como: bibelôs, retratos, painel de memórias que se fundem ao ato solitário e silencioso da leitura.

Logo, segundo Petit:

No interior da França, para empregar uma imagem, poderíamos dizer que, no decorrer do século XX, o leitor (que com frequência é uma leitora) levantou-se discretamente, deixou a sala de convívio e retirou-se em seu quarto. A leitura - que era, de início, uma atividade que se prescrevia para enredar as pessoas na malha das palavras - converteu-se em um gesto de afirmação de singularidade. Tornou-se um atalho, cada vez mais utilizado, para escapar do tempo e do lugar em que supostamente se deveria estar; escapar desse lugar predeterminado, dessa vida estática e do

\footnotetext{
${ }^{3}$ Termo proferido pelo professor Max Butlen nos Seminários Especiais Temáticos do PPG Letras da Universidade de Passo Fundo em maio de 2016.
} 
Entendemos, assim, que as leituras realizadas no interior do quarto são aquelas que requerem isolamento. Com isso, "a leitura silenciosa não pode ser exposta ao olhar de outrem: refugiam-se num espaço fechado que dissimula (o escritório) ou protege a intimidade (o quarto) e exige a eliminação de todos os vestígios que possam denunciá-la" (CHARTIER, 1999, p. 144). A leitura na intimidade propicia audácias, libera o leitor das antigas mediações, Ihe autorizar o recolhimento, a introspecção, a formulação de segredos, ou seja, pode se tornar "um atalho privilegiado para elaborar ou manter um espaço próprio, um espaço íntimo, privado" (PETIT, 2013, p. 41).

Outro lugar de leitura mencionado no interior da casa é a sala. Isto significa que os acadêmicos que optam por ler nesse espaço nos dão indícios de que tal espaço quem sabe seja o mais iluminado da casa como também o mais confortável para o ato de ler. Outra possibilidade é que as leituras realizadas na sala talvez não sejam tão privadas, podendo ser compartilhadas com os demais membros da família, tal como jornais, revistas, livros religiosos e até mesmo a Bíblia.

De acordo com Chantal Horellou-Lafarge e Monique Segré (2010), a prática da leitura se transforma conforme o efeito das mudanças nas maneiras de morar (da sala coletiva onde todos comem, vivem e dormem para as unidades individuais e separadas, que propiciam a intimidade) e da passagem de um modo de vida coletivo para uma vivência familiar privada e reduzida aos parentes próximos. A leitura, assim, conforme tais estudiosos, torna-se uma prática individual, particular, concentrada e as maneiras de ler, bem como os comportamentos durante tal atividade, seja de manifestar ou esconder suas impressões, de controlar as emoções correspondem a normas sociais interiorizadas.

Ao voltarmos nossos olhos para a história da leitura, notaremos que o ato de ler, por muito tempo, esteve imerso numa ideologia totalmente religiosa, sendo vista como perigosa e desnecessária. Mesmo com a disseminação da imprensa, ler ficção, os romances-folhetins publicados diariamente era perda de tempo. Esse fator se intensificava ainda mais por serem condenadas por autoridades morais da época: a Igreja proibia a leitura aos fiéis; as autoridades laicas afirmavam com convicção de que as histórias e a linguagem empregada eram pobres e vulgares; os educadores denunciavam a imoralidade e nocividade da leitura.

O mercado de livros só passou a se tornar um investimento rentável com o surgimento de um público capaz de consumir tal produto. Logo, os consumidores precisavam dominar a 
habilidade de ler, prática fortalecida através da obrigatoriedade do ensino escolar. A expansão da leitura também contava com outras duas grandes mudanças: as revoluções burguesas ocorridas dos séculos XVIII a XIX e a valorização da família. Assim, a leitura estava ligada à linguagem sagrada e àqueles que a detinham, eram os responsáveis por conduzir os leitores em tal atividade. Esse movimento geralmente acontecia na sala, onde o material a ser lido poderia ser do conhecimento em comum entre todos ali presentes.

De acordo com Anne-Marie Chartier (2016), ao longo do século XIX, na França, várias editoras criaram coleções destinadas às crianças e jovens, recrutando alguns escritores especializados para esse público. A clientela era composta por filhos de pessoas privilegiadas financeiramente, considerando o tempo livre das crianças e dos pais para sua educação. $\mathrm{Na}$ escola, a leitura não parecia seguir um caminho fadado ao sucesso, pois o ato de ler se revelava pouco dinâmico em relação às brincadeiras e conversas com amigos. Para a maioria dos professores "a leitura era importante porque era uma ferramenta para se instruir, não porque era uma oportunidade de diversão. Eles consideravam os romances como histórias fúteis, ou pior, nocivas" (CHARTIER, 2016, p. 14).

Com o advento da primeira transformação iniciada na França em 1789, o Estado foi afastado das operações econômicas, possibilitando a independência do comércio e o liberalismo financeiro e, com isso, o capital livre usaria do mercado da maneira que the fosse conveniente. A queda do Absolutismo trouxe o surgimento da família burguesa e sua extrema valorização, já que tal instituição privada se constituiu como peça fundamental à exaltação da vida doméstica. É nesse espaço que se intensifica o gosto pela leitura, por constituir atividade adequada ao contexto privado da família.

A leitura, assim, se tornava fundamental para difundir a leitura da Bíblia, ou seja, necessária à formação moral das pessoas. Seja individual, ou coletiva, em voz alta, ou silenciosamente, a leitura do folhetim semanal, ou das Sagradas Escrituras, essa prática passa a integrar o cotidiano do lar burguês. A leitura ganha força e se institucionaliza também no meio rural, em que os primeiros livros de sucesso na infância europeia resultaram de contos populares circulantes entre os habitantes do campo. Do cordel ao folhetim, o surgimento da imprensa proporcionou que a leitura chegasse até à cidade, através do jornal, e consolidasse a propagação do romance. Segundo Marisa Lajolo e Regina Zilberman:

Foi nestas condições que os leitores, cada vez mais numerosos, se transformaram em público consumidor de uma mercadoria muito específica. Estes leitores de carne e osso, dos quais se ocupam os censos e 
que sustentam o negócio dos livros, passíveis, de serem historicizados e estudados estatisticamente, têm sua contrapartida textual: o leitor empírico, destinatário virtual de toda criação literária, é também direta ou indiretamente introjetado na obra que a ele se dirige. Assim, nomeado ou anônimo, converte-se em texto, tomando a feição de um sujeito com o qual se estabelece um diálogo, latente mas necessário (LAJOLO; ZILBERMAN, 1996, p. 16-17).

Percebemos que a leitura não era incentivada como artefato da fruição e do prazer de ler, mas como prática pedagógica e capitalista. Claro que devido a isso, a leitura se alastrou cada vez mais na nossa sociedade e, hoje, se tornou objeto fundamental na emancipação das pessoas.

Vale atentar que a maioria dos entrevistados são jovens de até 18 anos ou em idade de transição da adolescência para a vida adulta entre 19 e 23 anos. Isso nos permite entender que tais sujeitos podem estar numa fase de conflitos internos, tentando constituir suas identidades, em busca de atingir a maturidade. Desse modo, a opção por ler num espaço íntimo como o quarto revela muito sobre a subjetividade deste leitor, pois tal espaço passa a ser "sede do recolhimento e da intimidade" (GOULEMOT, 1991, p. 372). Certamente, os tipos de livros escolhidos pelos leitores para ler em tal espaço da casa são os de ficção, os quais permitem imaginação, sonhos, reflexão, pausa para pensamentos ou lembranças. Também, é possível considerar outras leituras como as de cunho teórico ou científico, uma vez que o quarto pode ser o lugar mais silencioso da casa para ler tais textos.

Segundo Alberto Manguel (1997), um livro que pode ser lido em particular e sobre o qual se pode refletir enquanto os olhos revelam o sentido das palavras não está mais sujeito às orientações ou esclarecimentos, à censura ou condenação imediata de um ouvinte. A leitura silenciosa permite a comunicação sem testemunhas entre o livro e o leitor, o que, de certa forma, fez com que essa modalidade de leitura fosse considerada perigosa. Este tipo de leitor, que lê em silêncio "tornou-se cego e surdo ao mundo, às multidões de passantes, às fachadas desbotadas dos edifícios. Ninguém parece notar um leitor que se concentra: retirado, absorto, o leitor torna-se lugar-comum" (MANGUEL, 1997, p. 59).

Além da sala e do quarto, existem, conforme apresentado pelos resultados do questionário aplicado, outras configurações espaciais que também revelam onde há a preferência para ler. Vale atentar que 61 dos acadêmicos respondentes alegaram que praticam a leitura na cozinha. Esse dado nos chama a atenção, pois 175 dos respondentes alegaram possuir renda mensal acime de meio salário mínimo até dois salários por pessoa e 115 respondentes, renda de até meio salário mínimo por pessoa. 
Com isso, podemos inferir que os acadêmicos que mencionaram praticar a leitura na cozinha, talvez a façam porque seja o único lugar em que haja mobiliário como a mesa que serve como suporte para os livros, cadernos, notebooks e outros materiais necessários para auxiliar na leitura como também conter boa iluminação como a sala. Vale atentar que a cozinha é um lugar de preparação, logo, além de ser utilizada para a elaboração do alimento, se tornou um lugar onde se pode estudar e ler. Neste espaço, também podem realizar leituras de ordem instrumental como livros de receitas e bulas de remédios.

Já os acadêmicos que disseram ler no escritório certamente o fazem por haver tal ambiente dentro de casa. Na nossa compreensão, tais sujeitos se reservam a um tipo de leitura acadêmica, profissional ou pessoal uma vez que o espaço se considera como mais reservado que requer concentração. Por outro lado, os que simpatizam com a leitura na varanda e no banheiro nos dão a inferir que o conteúdo do material que leem é mais descontraído como revistas dos mais variados assuntos, jornais, etc.

Esses resultados são um pouco preocupantes, pois um futuro professor que se ocupará da formação desde as Séries Iniciais, que é o caso do egresso de Pedagogia, perpassando o Ensino Fundamental até o Ensino Médio, responsabilidade do docente de Letras não deve somente se restringir às leituras de ordem desinteressada, prática ou de entretenimento.

Se atentarmos para a História Cultural, os espaços de leitura existem desde os primórdios da humanidade. Chartier (1998) em diálogo com Jean Lebrun ressalta que é a partir do momento em que a leitura é representada na fotografia e pelo cinema, em fins do século XVIII e início do século XIX, que sua liberdade da leitura se expande e se desenvolve. Embora durante muito tempo as imagens pictóricas representaram o leitor sentado e imóvel, com o passar do tempo foi permitido ver práticas de leitura menos controladas.

A partir dos enunciados de Chartier (1998) apreendemos que as práticas de leitura se desenvolveram nos mais diversos lugares. Assim, percebemos que a casa enquanto espaço para o ato de ler é, de certa maneira, frutífera, pois também permite ao leitor a liberdade de estar em contato com os textos de sua preferência e praticar a leitura na intimidade do seu lar.

De acordo com Bachelard (1993), do porão ao sótão, cada espaço da casa é significativo, pois ela conduz o fio de uma história, na narrativa de nossa história. A leitura, assim, contribui, de certa forma, para que isso ocorra, pois, os espaços onde nos envolvemos com ela, evidencia que tipo de leitura realizamos e em qual perfil leitor nos enquadramos.

Conforme Márcia Abreu (2001), imagens que representam leitores no fim do século XVIII e meados do século XIX evidenciam que os espaços onde se realizavam tal prática eram bastante heterogêneos: casas confortáveis, bibliotecas luxuosas; sofás e poltronas 
aconchegantes, mesas repletas de livros e papéis; jardins floridos, algum café. Homens, mulheres e crianças leem fundamentalmente livros - exceção feita a um ou outro retrato de homem lendo jornal. Mesmo que na maior parte das vezes não se possa reconhecer as obras lidas não há como confundi-las com panfletos ou folhas de anúncios.

A estudiosa também ressalta que esta associação entre leitura e enobrecimento do sujeito foi construída historicamente, tendo recebido forte impulso com a ascensão da burguesia. Homens e mulheres bem instalados socialmente parecem ter ficado satisfeitos em associar-se a certos sinais exteriores de sucesso: boas casas, belos vestidos, ambientes confortáveis, e livros.

Dando sequência à análise dos resultados da pesquisa, vale atentar que 6 acadêmicos alegaram não ler em casa, o que nos permite inferir que tais sujeitos não possuem tempo para realizar a leitura nesse local, ou não reconhecem tal espaço como um ambiente para ler.

Assim, termos essa visão acerca dos espaços de leitura dentro do lar é de suma importância, pois nos possibilita não só conhecer os lugares preferidos para praticar a leitura por tais sujeitos, futuros professores de Letras e de Pedagogia, mas também a compreender de que a formação inicial circunscrita ao âmbito universitário deverá desenvolver cada vez mais o hábito leitor e, consequentemente preparar tais estudantes para a profissão docente. Isso, talvez, requer uma reflexão sobre as estruturas de ensino como: o currículo das disciplinas, as práticas de ensino voltadas para a formação de leitores, o acesso às bibliotecas, a integração da teoria à prática, etc.

A leitura, então, nada mais é do que a representação de como uma determinada sociedade, num certo lugar e num delimitado tempo organizam e vivem a sua cultura. Nesse sentido, todo sujeito interpreta e tenta compreender as situações que acontecem ao seu redor. Embora a leitura não se restrinja ao livro, foram as suas modificações devido ao surgimento da palavra impressa que revolucionaram o pensamento e a cultura da humanidade e, influenciaram nos lugares e maneiras de ler.

\section{As maneiras de ler em espaços privados}

De acordo com Chartier (1998), toda a história da leitura supõe em seu princípio a liberdade do leitor que desloca e subverte aquilo que o livro Ihe pretende impor. Contudo, tal autonomia não é absoluta, ao contrário, ela é cercada por limitações oriundas das capacidades, convenções e hábitos que caracterizam as práticas de leitura. Os gestos, as posições se 
modificam conforme o tempo e o lugar, bem como no que diz respeito aos objetos lidos.

Conforme Márcia Abreu (2001), até alguns anos atrás não se imaginava que as formas de ler pudessem ter se alterado desde que o homem inventou maneiras de registrar conteúdos por escrito e formas de decifrá-los. Pensava-se que a leitura sempre fora praticada como hoje, em silêncio e solitariamente, favorecendo a concentração e o recolhimento. Supunha-se que, em todas as épocas, ler implicava pensar sobre textos e interpretá-los, exigindo habilidades superiores à capacidade para decifrar os sinais gráficos da escrita. Acreditava-se que o contato com os livros foi sempre valorizado por favorecer o espírito crítico, tornando o leitor uma pessoa melhor por meio do contato com experiências e ideias registradas por escrito.

Neste sentido, as práticas de leitura que se disseminaram ao longo do tempo são encarnadas em gestos, espaços, disposições e hábitos como postula o historiador do livro, Roger Chartier. Notamos que os acadêmicos de Letras e de Pedagogia enunciaram algumas posições de leitura que praticam em espaços privados como podemos observar na questão $54^{4}$ :

Quadro 2: Quanto à disposição física para a leitura, qual é/são a/s sua/s posição/ões mais frequente para ler em espaços privados?

\footnotetext{
${ }^{4}$ Os licenciandos participantes da pesquisa tinham a opção de assinalar mais de uma resposta, por isso o número dessas pode se apresentar superior ao total de sujeitos respondentes. Os acadêmicos poderiam assinalar uma ou mais respostas. Tal questão está inserida nos seguintes blocos temáticos: Perfil leitor e Espaços e Modos de ler.
} 


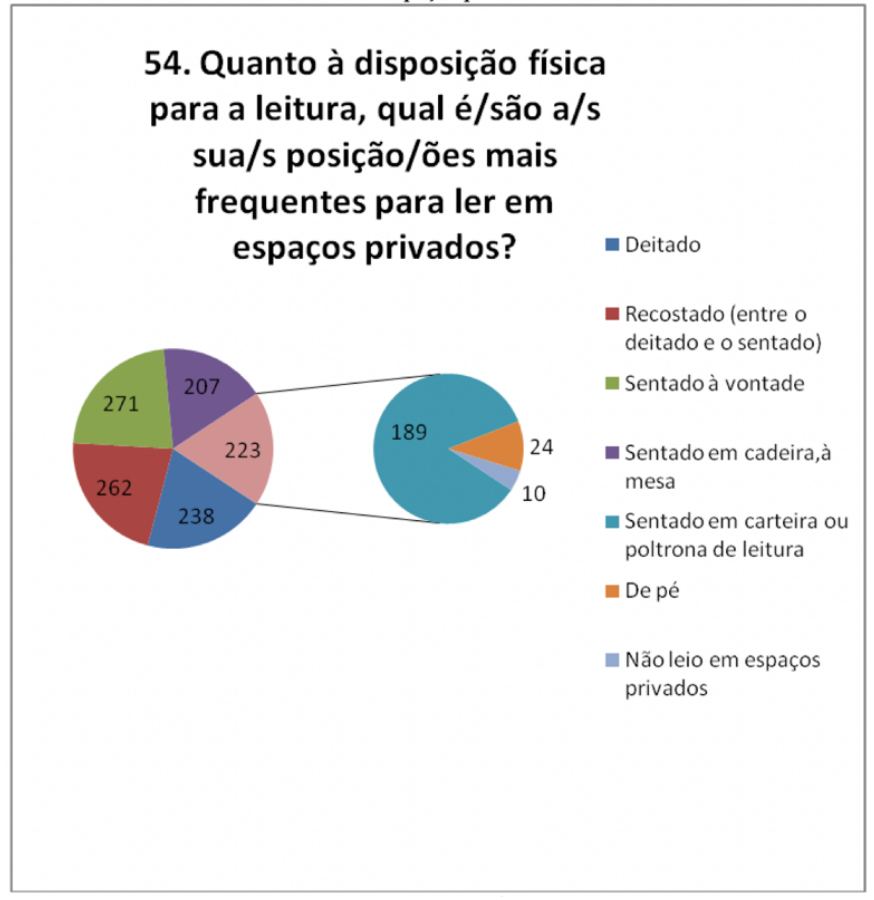

Fonte: Procad

O resultado obtido revelou que 238 respondentes alegaram ler deitados, 262 recostados (entre deitado e o sentado), 271 sentados à vontade, 207 sentado em cadeira, à mesa; 189, sentado em carteira ou poltrona de leitura, 24 em pé, 10 sujeitos mencionaram não ler em espaços privados.

Diante disso, podemos inferir em relação aos sujeitos responderam que praticam o ato de ler deitados e recostados, entre o deitado e o sentado, necessitam de certo conforto para praticarem a leitura. Tais percentuais que evidenciam uma maior liberdade desses leitores em relação à leitura mostram que, provavelmente isso ocorre, porque os textos, livros ou obras selecionados para ler são aqueles que propiciam a fruição, o gosto, o prazer de ler.

Notamos que tais sujeitos se permitem a uma maior flexibilidade e liberdade nas posições escolhidas para ler, quem sabe também pela distância de determinadas conveniências sociais, possibilitando-nos também inferir que os textos escolhidos para leitura neste espaço não estão sob o olhar do outro.

Conforme Chartier (1998, p. 78), foi a partir do século XVIII que os leitores (as) permitem-se comportamentos mais variados e livres, isto é, "[...] as imagens representam o leitor na natureza, o leitor que lê andando, que lê na cama [...]", o que significa afirmar que uma nova atitude percorre os momentos de leitura. Com isso, percebemos que o modo de ler no espaço 
privado não se circunscreve a uma leitura limitada, mas ampla, liberta de determinadas convenções. Certamente, isto se relaciona com as preferências de leituras dos respondentes da pesquisa do Procad.

De acordo com Jean Marie Goulemot (2001), existe na leitura de divertimento, bem como em toda leitura uma posição ou atitude do corpo: sentado, deitado, alongado, em público, solitário, em pé, etc., ou seja, uma disposição pessoal de cada um para a leitura. O estudioso menciona isso como um rito, pois somos um corpo leitor que cansa, fica sonolento, que boceja, experimenta dores, formigamentos havendo, assim, uma instituição do corpo que lê.

Já os acadêmicos que alegaram praticar a leitura sentados à vontade, em poltrona de leitura e em cadeira ou à mesa significa que possuem um comportamento mais reservado, imóvel em relação à leitura, certamente a praticam em alguns espaços da casa como cozinha, escritório ou também na sala e se dedicam a uma leitura que exige um certo grau de concentração. Notamos que ao longo do tempo "[...] os leitores anteriores ao século XVIII liam no interior de um gabinete, de um espaço retirado e privado, sentados e imóveis" (CHARTIER, 1998, p. 79). Esses leitores reproduzem um modo de ler elitizado muito praticado durante o Antigo Regime.

Conforme Márcia Abreu (2001), no fim do século XVIII e no decorrer do século XIX, os livros são parte importante na composição de retratos, indicando principalmente o poder social e a posição intelectual dos retratados que, em geral, são homens. Inúmeras são as obras em que senhores bem vestidos posam diante de uma biblioteca ou estante. Também indicando seu interesse intelectual alguns são vistos lendo jornais, em suas casas ou em espaços públicos. Nesse sentido, podemos entender que a leitura realizada no conforto da poltrona, na cadeira, à mesa evidencia uma postura elitizada, enobrecida.

Segundo Chartier:

$$
\begin{aligned}
& \text { O mobiliário do século XVIII dá os suportes adequados à leitura da } \\
& \text { intimidade. A poltrona, dotada de braços e guarnecida de almofadas, a } \\
& \text { chaise-longue ou espreguiçadeira, a espreguiçadeira cortada com seu } \\
& \text { tamborete separado são, igualmente, novos assentos onde o leitor, mais } \\
& \text { freqüentemente a leitora, pode se instalar à vontade e abandonar-se ao } \\
& \text { prazer do livro. [...] Outros móveis implicam uma leitura menos relaxada, } \\
& \text { como as mesas de base móvel onde se pode colocar o livro, assim como o } \\
& \text { papel de escrita ou os bonheur-du-jour, escrivaninhas que podem ter uma } \\
& \text { pequena biblioteca superposta (CHARTIER, 2001, p. 91). }
\end{aligned}
$$

Notamos, então, que muitos gestos, posturas e lugares os quais continuam sendo utilizados na contemporaneidade e vivenciados pelos acadêmicos de Letras e de Pedagogia são oriundos do Antigo Regime. A leitura, deste modo, "é uma das práticas constitutivas da 
intimidade individual, remetendo o leitor a si mesmo, a seus pensamentos ou a suas emoções, na solidão e no recolhimento" (CHARTIER, 1991, p. 151).

No que diz respeito aos 24 acadêmicos que responderam praticar a leitura em pé, podemos interpretar que os textos lidos são aqueles que não exigem grande concentração, não necessitam de anotações e seja uma leitura rápida. Outra inferência pode ser a leitura no suporte digital, uma vez que devido à grande disseminação dos aparelhos tecnológicos, tornou-se comum as pessoas lerem em pé com smartphones e/ou tablets nas mãos.

Por fim, apenas 10 respondentes alegaram não ler em espaços privados. Talvez, pelos seguintes motivos: ausência de material de leitura, não terem gosto pela leitura, não se sentirem à vontade, etc.

Se atentarmos para a questão 51 a qual questionou sobre os espaços onde os sujeitos respondentes da pesquisa alegaram ler em casa, podemos perceber que os ambientes mencionados como o quarto, a sala, o escritório, a cozinha e o banheiro permitem a essas pessoas utilizar as posições para ler em lugares privados apresentadas na questão 54 .

Cabe observar que os dados obtidos reforçam o que Márcia Abreu discute sobre os modos de ler em determinados espaços. Isto é, que os registros iconográficos que datam fins do século XVIII e o decorrer do século XIX evidenciam que as disposições físicas utilizadas nas práticas de leitura, nessa época, nos são familiares nos dias de hoje e, por meio do resultado da pesquisa do Procad foram experienciadas pelos acadêmicos de Letras e de Pedagogia, respondentes da pesquisa.

\section{Considerações finais}

Neste artigo, descrevemos e analisamos os espaços e maneiras de ler, especialmente os que se referem ao ato de ler no espaço da casa e as disposições físicas de leitura em ambientes privados dos estudantes ingressantes nas licenciaturas de Letras e de Pedagogia das três universidades brasileiras integrantes do Procad. Os dados aqui apresentados foram resultado de uma pesquisa desenvolvida na Universidade de Passo Fundo (UPF) entre os anos de 2015 e 2019.

Os resultados nos permitiram perceber que há uma preferência pelo ambiente interno da casa, provavelmente pela privacidade e por disporem de artefatos necessários para auxiliar na leitura como conforto, mobiliário, etc., por tal espaço propiciar uma maior intimidade 
dependendo do tipo de leitura praticada, ou também por necessidade.

Diante disso, entendemos que a casa assume um espaço significativo na vida desses sujeitos enquanto leitores. Em tal ambiente, a identidade do indivíduo é concretizada e, talvez, no caso dos respondentes da pesquisa, se torna o lugar onde eles constroem uma trajetória de leitura nos espaços interiores que possuem para isso. Logo, conforme Gaston Bachelard (1993), a casa, é um dos maiores poderes de integração para os pensamentos, as lembranças e os sonhos do homem.

Em relação às disposições físicas de leitura, os resultados do questionário aplicado mostraram que a maioria dos respondentes optou por posições mais libertas de determinadas convenções quando leem em espaços privados. Ou seja, ocorre uma maior liberdade corporal em relação ao texto quando o ato de ler é executado em ambientes recônditos. Podemos interpretar que esse resultado pode se relacionar com os espaços interiores da casa nos quais os sujeitos da pesquisa alegaram praticar a leitura. Mas também, muitos respondentes ainda reproduzem as posições de leituras dos leitores do Antigo Regime: sentados confortavelmente em poltrona ou em cadeira, à mesa. Os resultados das questões analisadas, então, vão de encontro com o que preconizam os estudos de Roger Chartier e Márcia Abreu acerca dos espaços e maneiras de ler.

Portanto, ressaltamos a importância de os professores universitários das licenciaturas de Letras e de Pedagogia das universidades do Procad e de outras instituições de ensino superior que tenham o interesse pelo assunto aqui abordado, ao tomarem conhecimento dos resultados obtidos nessa pesquisa, desenvolverem ações metodológicas que envolvam o ato de ler dos diversos tipos e gêneros textuais, em diferentes espaços e disposições físicas de leitura, a fim de alavancar a qualidade na formação leitora e ampliar o repertório de leitura dos respondentes da pesquisa, futuros professores. Com isso, esses sujeitos, ao exercerem a docência poderão ter conhecimentos mais profundos acerca das práticas de leitura e, consequentemente, formar leitores no contexto escolar.

\section{Referências}

ABREU, M. Diferentes formas de ler. In: XXIV CONGRESSO BRASILEIRO DE CIÊNCIAS DA COMUNICAÇÃO, 2001, Campo Grande. Mesa-redonda Práticas de Leituras: histórias e modalidades. Disponível em: <http://www.unicamp.br/iel/memoria/Ensaios/Marcia/marcia.htm>. Acesso em: 25. Fev. 2018.

BACHELARD, G. A poética do espaço. São Paulo: Martins Fontes, 1993.

CHARTIER, R. As práticas de escrita. In: ÀRIES, P.; CHARTIER, R. (Org.). História da vida privada 3: da Renascença ao Século das Luzes. Trad. Hildergard Feist. São Paulo: Companhia das Letras, 1991. p. 113- 
161.

A aventura do livro: do leitor ao navegador: conversações com Jean Lebrun. Trad. Reginaldo Carmello Corrêa de Moraes. São Paulo: Editora UNESP, 1998.

A ordem dos livros: leitores, autores e biblioteca na Europa entre os séculos XIV e XVIII. Brasília: Editora Universidade de Brasília, 1999.

Do livro à leitura. In: CHARTIER, Roger (Org.). Práticas de leitura. Trad. Cristiane Nascimento. 2. ed. São Paulo: Estação Liberdade, 2001. p. 77-105.

CHARTIER, A. M. Como fazer os jovens lerem? Olhar histórico sobre o caso francês de incentivos à leitura. In: RÖSING, T.; ZILBERMAN, R. Leitura: história e ensino. 1. ed. Porto Alegre, RS: Edelbra, 2016. p. 13-34.

CHARTIER, A. M.; CHARTIER, R. Conferência a duas vozes. In: CHARTIER, A. M. ... [et al]; RÖSING, T. M. K. (Org.). Literatura e identidade na era da mobilidade. Passo Fundo: Ed. Universidade de Passo Fundo, 2016b. p. 59-87.

GINZBURG, Carlo. Sinais: raízes de um paradigma indiciário. In:___. Mitos, emblemas, sinais: morfologia e história. Trad. Federico Carotti. São Paulo: Companhia das Letras, 1989.

GOULEMOT, J. M. As práticas literárias ou a publicidade do privado. In: ÁRIES, P.; CHARTIER, R. (Org.). História da vida privada 3: da Renascença ao Século das Luzes. Trad. Hildegard Feist. São Paulo: Companhia das Letras, 1991. p. 371-405.

Da leitura como produção de sentidos. In: CHARTIER, Roger (Org.). Práticas de leitura. Trad. Cristiane Nascimento. 2. ed. São Paulo: Estação Liberdade, 2001. p. 106-116.

HORELlOU-LAFARGE, C.; SEGRÉ, M. Sociologia da leitura. Trad. Mauro Gama. Cotia, SP: Ateliê Editorial, 2010.

HOUAISS, A.; VILLAR, M. S.; FRANCO, F. M. M. Dicionário da Língua Portuguesa. 2. ed. Rev. e Aum. Rio de Janeiro: Objetiva, 2004.

JOUVE, V. A leitura. Trad. Brigitte Hervor. São Paulo: Editora UNESP, 2002.

LAJOLO, M.; ZILBERMAN, R. A formação da leitura no Brasil. São Paulo: Ática, 1996.

MANGUEL, A. Uma história da leitura. Trad. Pedro Maia Soares. São Paulo: Companhia das Letras, 1997.

PETIT, M. A arte de ler ou como resistir à adversidade. Trad. Arthur Bueno e Caminha Boldrini. $1^{\text {a }}$ ed. São Paulo: Ed. 34, 2009. $\overline{2013 .}$.

Leituras: do espaço íntimo ao espaço público. Trad. Celina Olga de Souza. São Paulo: Editora 34,

POULAIN, M. Cenas de leitura na pintura, na fotografia, no cartaz, de 1881 a 1989. In: FRAISSE, E.; POMPOUGNAC, J. C.; POULAIN, M. (Org.). Representações e imagens de leitura. Trad. Osvaldo Biato. São Paulo: Editora Ática, 1989. 
Recebido 10/08/2019 e aprovado em 02/12/2019. 